DOI: 10.17516/1997-1397-2021-14-6-779-786

УДК 539.3; 539.42

\title{
Fracture of Protective Structures from Heavy Reinforcing Cement During Interaction with High-velocity Impactor
}

\author{
Pavel A. Radchenko* \\ Stanislav P. Batuev ${ }^{\dagger}$ \\ Andrey V. Radchenko $\ddagger$ \\ Institute of Strength Physics and Materials Science SB RAS \\ Tomsk, Russian Federation
}

Received 10.04.2021, received in revised form 10.06.2021, accepted 20.08.2021

\begin{abstract}
In this work, the fracture of a reinforced concrete barrier made of heavy reinforced cement is numerically simulated during normal interaction with a high-velocity titanium projectile. The projectile has the initial velocity $750 \mathrm{~m} / \mathrm{s}$. The problem of impact interaction is numerically solved by the finite element method in a three-dimensional formulation within a phenomenological framework of solid mechanics. Numerical modeling is carried out using an original EFES 2.0 software, which allows a straightforward parallelization of the numerical algorithm. Fracture of concrete is described by the Johnson-Holmquist model that includes the strain rate dependence of the compressive and tensile strengths of concrete. The computational algorithm takes into account the formation of discontinuities in the material and the fragmentation of bodies with the formation of new contact and free surfaces. The behavior of the projectile material is described by an elastoplastic medium. The limiting value of the plastic strain intensity is taken as a local fracture criterion for the projectile material. A detailed numerical analysis was performed to study the stress and strain dynamics of the reinforced concrete target and the effect of shock-wave processes on its fracture. The influence of reinforcement on the resistance of a heavy cement target to the penetration of a projectile has been investigated.
\end{abstract}

Keywords: model, fracture, strength, shock wave, unloading wave, concrete, stress.

Citation: P.A. Radchenko, S.P. Batuev, A.V. Radchenko, Fracture of protective structures from heavy reinforcing cement during interaction with high-velocity impactor, J. Sib. Fed. Univ. Math. Phys., 2021, 14(6), 779-786. DOI: 10.17516/1997-1397-2021-14-6-779-786.

\section{Introduction}

Reinforced cement structures are a type of reinforced concrete structures made of concrete, which includes cement-sand concrete reinforced with nets made of thin wire 0.5-1 mm in diameter with small cells up to 10x10 mm in size. By heavy reinforced cement we mean reinforced concrete structures with close-packed reinforcement, in which metal rods with a diameter of more than 5 $\mathrm{mm}$ are used for reinforcement.

Reinforced concrete is the most widespread construction material, which is much used in the construction of buildings and structures. Requirements on physical and mechanical characteristics of concrete depend on its application, operating conditions, and the criticality level of structures. For designing major risk structures (nuclear power plants, hydroelectric dams, storage facilities for toxic and radioactive materials, and protective shelters), prediction calculations must be made for their dynamic load - shock, impulse action [1]. Such loads on a structure

\footnotetext{
* https://orcid.org/0000-0002-1879-9143

$\dagger$ https://orcid.org/0000-0002-8142-7385

‡andrey-radchenko@live.ru https://orcid.org/ 0000-0002-3105-471X

(C) Siberian Federal University. All rights reserved
} 
can be induced by natural phenomena (earthquakes, hurricanes), man-made disasters (aircraft crashes), operational failures, and terrorist attacks.

The behavior of concrete under severe dynamic loads is significantly different from the behavior under static loads. This is due to strength properties of concrete: high compressive strength but low tensile strength. The difference in compressive and tensile strengths of concrete can reach a factor of 15-20. Under severe dynamic loading (high-velocity impact, impulsive loads), wave processes take on a decisive role in fracture of concrete, resulting in zones of intensive tensile stresses, which arise in unloading waves. Discontinuities will form in these zones, which can end in fracture and fragmentation of a structure. Metal, basalt, glass and carbon fibers are currently used to improve strength characteristics of concrete. Reinforcing steel elements are replaced by composite ones, thus reducing significantly the structure weight and retaining the operational characteristics. The experimental, theoretical and numerical study of the concrete behavior under dynamic load is proceeding vigorously. The work is carried out in several directions: development of simplified models based on the experimental investigation of various concrete types, which enable a rapid assessment of dynamic action on a structure; development of reinforced concrete models; development of algorithms for detailed numerical analysis and prediction calculations [2-9]. Pereira et al. [2] proposed a concrete damage model, which takes into account the influence of hydrostatic compression on the concrete fracture under impact loads. The numerical comparison in an axisymmetric formulation was made of fracture dynamics of concrete targets under normal impact of the rigid and elastoplastic projectile in the range of initial velocities $200-500 \mathrm{~m} / \mathrm{s}$. The numerical results show satisfactory agreement with the experiments on the fracture pattern of concrete targets at various impact velocities and target thicknesses. Teng et al. [3] performed numerical modeling by the finite element method in a three-dimensional formulation for normal and oblique interaction of the ogival-nosed steel projectile with the reinforced concrete target in the velocity range $300-1000 \mathrm{~m} / \mathrm{s}$. Concrete was reinforced with cylindrical steel rods spaced evenly in one or two orthogonal directions. Reinforcing elements were given no explicit consideration in the model. A heterogeneous reinforced concrete target was replaced by an orthotropic elastic-brittle medium with effective mechanical characteristics. The investigation focused on fracture of the reinforced concrete target under normal and oblique impact. The influence of reinforcement on the ballistic resistance of concrete targets was experimentally studied by Iqbal et al. [4] for the case of normal interaction of long high-strength ogival-nosed steel rods with concrete and reinforced concrete targets at the velocity $90-180 \mathrm{~m} / \mathrm{s}$. The experiments show that the concrete target reinforcement increases its ballistic resistance by $20 \%$. Zhang et al. [5] proposed an analytical model for the penetration of ogival-nosed projectiles into semi-infinite concrete targets at different interaction velocities. Several intervals of impact velocities were introduced, in which the projectile behavior is described differently depending on the physical and mechanical properties of the material: at low velocities, the projectile is thought to be absolutely rigid; with increasing velocity, consideration is given to erosion and loss of mass of the projectile; at high velocities, the projectile is assumed to be deformable, with the nose part being transformed into a spherical one. Works on numerical modeling often employ commercial software. Shao et al. [6] performed a numerical LS-DYNA investigation of the interaction of steel projectiles with the three-layered target at the velocities up to $810 \mathrm{~m} / \mathrm{s}$. The upper layer consists of the steel mesh, the second layer is foamed aluminum, and the third layer is high-strength concrete. Account was taken of an increase in the concrete strength at higher strain rate. The influence of the metal mesh and foamed aluminum on the energy absorption of the layered target and fracture of concrete was investigated. The depth and diameter of the crater formed in concrete was compared to the experimental data. A comprehensive study was performed by Rajput et al. [7], including the numerical and experimental investigation of the influence of reinforcement on the ballistic resistance of concrete targets. The steel mesh with the bar diameter $8 \mathrm{~mm}$ was used for reinforcement. High-strength steel projectiles with the diameter $19 \mathrm{~mm}$, mass 0.5 and $1.0 \mathrm{~kg}$, aspect ratio 11.8 and 23.7 , respectively, were 
used as strikers. Interaction velocities varied in the range $43-178 \mathrm{~m} / \mathrm{s}$. It was shown that the concrete target reinforcement increases the ballistic limit by $15.6 \%$ for the $0.5 \mathrm{~kg}$ projectile and by $13 \%$ for the $1 \mathrm{~kg}$ projectile. The influence of fibers on the concrete strength was studied by Liu et al. [8], where the influence of steel and polymer fibers on the concrete impact resistance was studied numerically and experimentally. The fiber concentration in the concrete was $3 \%$, providing the maximum increase in the concrete strength. The reinforced concrete is struck by ogival-nosed projectiles made of high-strength steel with the yield strength 1.5 GPa. The impact velocity ranged $550-800 \mathrm{~m} / \mathrm{s}$. A comparative analysis was performed for the ballistic resistance of the targets made of conventional concrete and concrete reinforced with various fibers. It was shown that the introduction of fibers significantly increases the impact strength of concrete. The strongest effect was achieved with steel fibers. Along with the solution of the problem of strength improvement, effective means of fracture of concrete structures are searched for. One way is to use two-stage projectiles [9]. An explosively formed projectile impacts the structure at the first stage, and a high-strength projectile acts at the second stage. After the shock wave partially destroys the structure, the solid projectile penetrates into it. Such projectiles are employed to destroy underground structures. The effect of such projectiles was investigated experimentally and numerically in the LS-DYNE code [9].

The purpose of our work is to study the fracture of a reinforced concrete structure made of heavy reinforced cement upon impact. The structure consists of close-packed steel reinforcement and cement-sand concrete. In the calculations, the diameter of the reinforcing bars and the size of the cells vary. In the calculations, reinforcing elements are taken into account explicitly.

\section{Basic equations of the mathematical model}

The system of equations describing nonstationary adiabatic motion of the compressed medium in the arbitrary coordinate system $(i=1,2,3)$, includes the following equations: continuity equations

motion equations

$$
\frac{\partial \rho}{\partial t}+\rho \nabla_{i} v^{i}=0,
$$

$$
\rho a^{k}=\nabla_{i} \sigma^{i k}+F^{k},
$$

where

$$
\begin{gathered}
a^{k}=\frac{\partial v^{k}}{\partial t}+v^{i} \nabla_{i} v^{k} \\
\nabla_{i} \sigma^{i k}=\sigma_{, i}^{i k}+\Gamma_{i m}^{k} \sigma^{i m}+\Gamma_{i m}^{m} \sigma^{i k}
\end{gathered}
$$

and energy equations

$$
\frac{\mathrm{d} E}{\mathrm{~d} t}=\frac{1}{\rho} \sigma^{i j} e_{i j} .
$$

Here $F^{k}$ is the mass force vector components, $\Gamma_{i j}^{k}$ is the Christoffel symbols, $\sigma^{i j}$ is the contravariant components of the symmetric stress tensor, $E$ is the specific internal energy, $\rho$ is the medium density, $v^{i}$ is the velocity vector components, and $e_{i j}$ is the symmetric strain rate tensor components:

$$
e_{i j}=\frac{1}{2}\left(\nabla_{i} v_{j}+\nabla_{j} v_{i}\right) .
$$

The stress tensor is represented as a sum of the deviatoric $S^{k i}$ and spherical parts $P$ :

$$
\sigma^{i j}=-P g^{i j}+S^{i j},
$$

where $g^{i j}$ is the metric tensor. 
Pressure in the projectile material is calculated via the Mie-Gruneisen equation as a function of the specific internal energy $E$ and density $\rho$ :

$$
P=\sum_{n=1}^{3} K_{n} \mu^{n}\left(1-\frac{K_{0} \mu}{2}\right)+K_{0} \rho E,
$$

where $K_{0}, K_{1}, K_{2}, K_{3}$ are the material constants, $\mu=V / V_{0}-1, V_{0}$ and $V$ are the initial and current specific volumes.

Pressure in the concrete target is determined by the equation

$$
P=\left\{\begin{array}{l}
K_{1} \mu+K_{2} \mu^{2}+K_{3} \mu^{3}, \quad \mu>0, \\
K_{1} \mu, \mu \leqslant 0
\end{array}\right.
$$

By assuming the principle of minimum work of true stresses in a strain increment, the relation between the strain rate tensor components and stress deviator is written in the form

$$
2 G\left(e_{i j}-\frac{1}{3} e_{k k} \delta_{i j}\right)=\frac{\mathrm{D} S^{i j}}{\mathrm{D} t}+\lambda S^{i j}, \lambda \geqslant 0 .
$$

Here the time derivatives of the deviatoric stress components are taken in the Jaumann formulation:

$$
\frac{\mathrm{D} S^{i j}}{\mathrm{D} t}=\frac{\mathrm{d} S^{i j}}{\mathrm{~d} t}-S^{i k} \omega_{j k}-S^{j k} \omega_{i k},
$$

where $\omega_{i j}=\left(\nabla_{i} v_{j}-\nabla_{j} v_{i}\right) / 2$ and $G$ is the shear modulus.

The material shows elastic behavior $(\lambda=0)$ subject to the Mises condition

$$
S^{i j} S_{i j} \leqslant \frac{2}{3} \sigma_{\mathrm{d}}^{2}
$$

and plastic behavior $(\lambda>0)$ provided that the Mises condition does not hold. Here $\sigma_{d}$ is the dynamic yield stress of steel, which, in a general case, can be a function of strain rate, pressure and temperature.

The limiting plastic strain intensity is taken to be a local fracture criterion for the projectile material:

$$
e_{\mathrm{u}}=\frac{\sqrt{2}}{3} \sqrt{3 T_{2}-T_{1}^{2}}
$$

where $T_{1}$ and $T_{2}$ are the first and second strain tensor invariants.

The experimental investigations of concrete fracture revealed an increase in strength characteristics of concrete under dynamic loads [10]. In so doing, the ultimate tensile and compressive stresses depend differently on the strain rate. The static ultimate strength is related to dynamic one via the dynamic response factor $K_{d}=R_{d} / R_{s}$, where $R_{d}$ is the dynamic strength, and $R_{s}$ is the static strength.

Based on the experimental data [10], approximation dependences were derived for dynamic response factors of concrete in compression (10) and tension (11). The corresponding $K_{d}-e$ diagrams are given in Fig. 1:

$$
\begin{gathered}
K_{\mathrm{dt}}=0.00158333 e^{5}+0.0252855 e^{4}+0.15255 e^{3}+0.47898 e^{2}+1.01959 e+2.36037 \\
K_{\mathrm{dc}}=0.000832308 e^{5}+0.0110547 e^{4}+0.0447734 e^{3}+0.0475887 e^{2}+0.0184316 e+1.20895 .
\end{gathered}
$$

Concrete fracture is described using the Johnson-Holmquist model [11, 12] with consideration for damage accumulation in compression:

$$
\frac{\mathrm{d} D}{\mathrm{~d} t}=\frac{\mathrm{d} \varepsilon_{\mathrm{p}}}{\mathrm{d} t} \frac{1}{\varepsilon_{\mathrm{p}}^{\mathrm{f}}}
$$




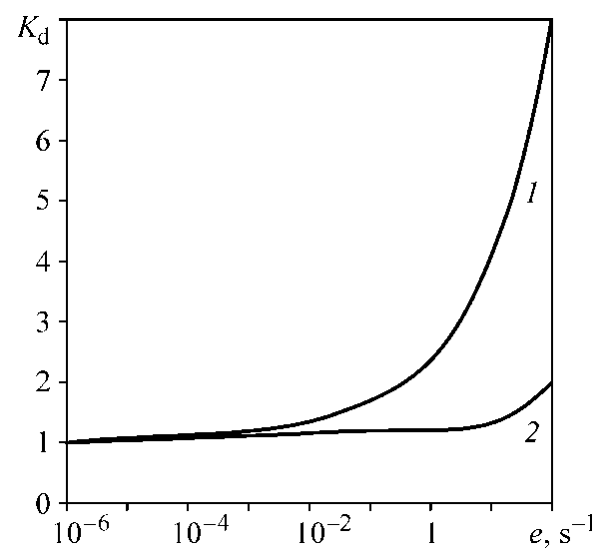

Fig. 1. Dynamics response factor versus strain rate in tension (1) and compression (2).

where $D$ is the damage parameter characterizing the degree of discontinuity of the material, $\varepsilon_{\mathrm{p}}$ is the equivalent ultimate plastic strain of the material and $\varepsilon_{\mathrm{p}}^{\mathrm{f}}$ is the cracking strain:

$$
\varepsilon_{\mathrm{p}}^{\mathrm{f}}=D_{1}\left(P^{*}+T^{*}\right)^{D_{2}}
$$

where $D_{1}, D_{2}$, and $T^{*}$ are the experimental parameters of the material, $P^{*}=P / P_{H E L}$ is the normalized pressure, and $P_{H E L}$ is the Hugoniot pressure. At $D=1$, the material is thought to be fractured, and in so doing $\sigma_{i j}=0$.

Tensile fracture occurs in concrete if the highest normal stress exceeds the dynamic ultimate tensile strength:

$$
\max \left\{\sigma^{11}, \sigma^{22}, \sigma^{33}\right\} \geqslant K_{\mathrm{dt}} R_{\mathrm{t}}
$$

\section{Problem statement}

Consideration is given to the normal interaction of the cylindrical titanium projectile with the reinforced concrete target. The projectile density $\rho_{0}=4430 \mathrm{~kg} / \mathrm{m} 3$ and dynamic yield stress $\sigma_{d}=0.9 \mathrm{GPa}$. The projectile is $50 \mathrm{~mm}$ in diameter, $100 \mathrm{~mm}$ in length, and has the initial velocity $750 \mathrm{~m} / \mathrm{s}$. The target material is concrete with the density $\rho_{0}=2440 \mathrm{~kg} / \mathrm{m} 3$ compressive $R_{c}=48 \mathrm{MPa}$ and tensile strengths $R_{t}=4.8 \mathrm{MPa}$. The target is a parallelepiped with a length $150 \mathrm{~mm}$, width $150 \mathrm{~mm}$ and thickness $100 \mathrm{~mm}$. The target is reinforced with metal rods with dynamic yield stress $\sigma_{d}=0.3 \mathrm{GPa}$ and density $\rho_{0}=7850 \mathrm{~kg} / \mathrm{m} 3$. Two cases of reinforcement were considered, the first - the reinforcement diameter of $5 \mathrm{~mm}$ (Fig. 2a), the second - the reinforcement diameter of $10 \mathrm{~mm}$ (Fig. 2b). In the first case, the distance between the rods is $20 \mathrm{~mm}$, in the second $-50 \mathrm{~mm}$. In both cases, the reinforcement simulated exlplicitly.

The problem is solved numerically in a three-dimensional statement in the Cartesian coordinate system by the finite element method [13-15] using the original EFES 2.0 software [16]. The condition of frictionless sliding is realized at the target - projectile contact surface.

\section{Modeling and results}

In accordance with the task, a numerical simulation of the interaction of a titanium projectile with two types of targets was carried out (Fig. 2). As noted above, the calculations were carried out with an explicit description of reinforcing elements. In target 1 , the reinforcement is denser the reinforcement volume is $33 \%$, in barrier $2-22 \%$. Fig. 3 shows the calculated configurations of 

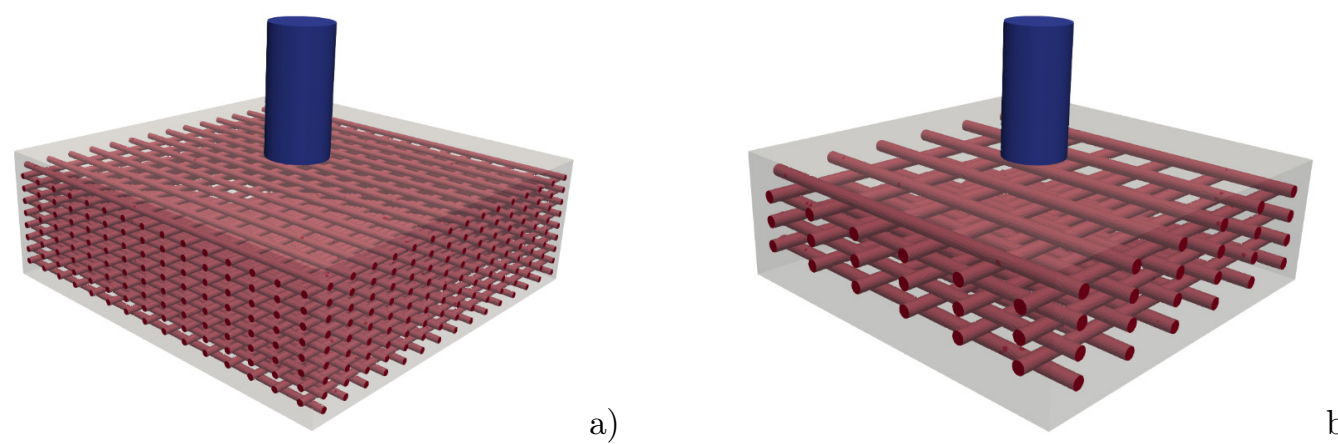

b)

Fig. 2. Formulation of the problem. a) - target 1, b) - target 2

the projectile and target 1 at 65 and $130 \mu$ s after the start of interaction. The given configurations illustrate the dynamics of targets fracture. Calculations show that intensive fracture of concrete occurs along the thickness of the barrier. Also, concrete is fractured in planes perpendicular to the direction of impact, the size of the fracture area is three diameters of the projectile. Intense fracture of concrete occurs in unloading waves resulting from multiple reflections of compression waves from contact and free boundaries. The tensile strength of concrete is low, which leads to its fracture in unloading waves.

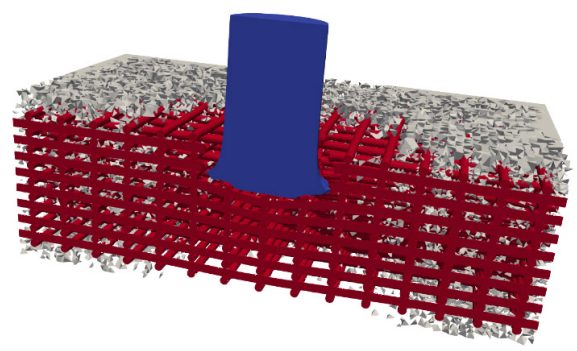

a)

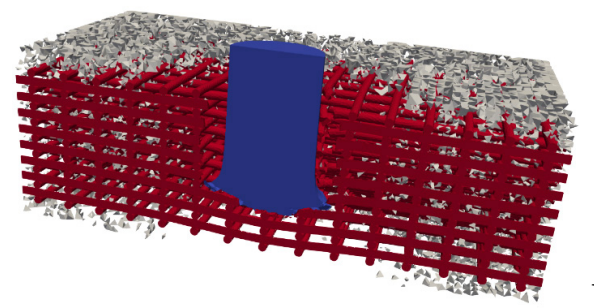

b)

Fig. 3. The configurations of the projectile and target 1 at the moments of time a) $65 \mu \mathrm{s}$, b) $130 \mu \mathrm{s}$

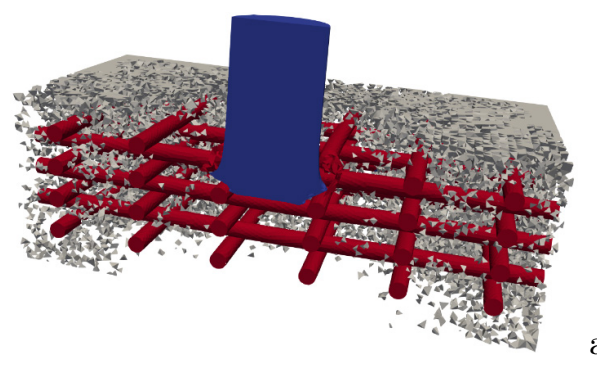

a)

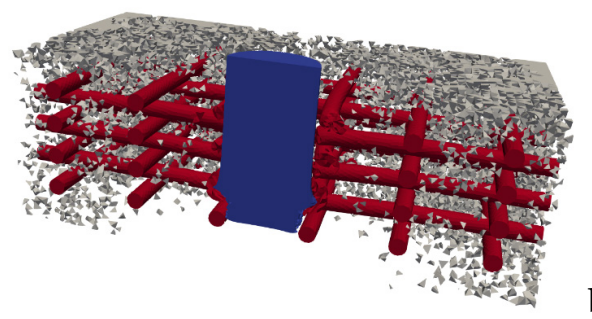

b)

Fig. 4. The configurations of the projectile and target 2 at the moments of time a) $65 \mu \mathrm{s}$, b) $130 \mu \mathrm{s}$

Similar to Fig. 3 in Fig. 4 shows the configuration of the projectile and target 2 . The qualitative picture of the fracture of target 2 is the same as target 1 . The resistance of targets to impact fracture can be estimated from the values of the velocity of the center of mass of the projectile and the depth of penetration of the projectile. The penetration depths of the projectile into target 1 at 65 and $130 \mu$ s were 37 and $74 \mathrm{~mm}$, respectively. For target 2, the values of the 
penetration depth at the same times were 39 and $81 \mathrm{~mm}$, respectively, which is $5 \%$ and $9 \%$ more than in target 1.

The velocity of the center of mass of the projectile when interacting with target 1 in $65 \mu \mathrm{s}$ was $625 \mathrm{~m} / \mathrm{s}$, in $130 \mu \mathrm{s}-528 \mathrm{~m} / \mathrm{s}$. The corresponding values of the projectile's velocity when interacting with target 2 are 665 and $619 \mathrm{~m} / \mathrm{s}$, which is $6 \%$ and $17 \%$ more than in target 1 . Thus, target 1 has greater resistance to the projectile's penetration.

\section{Conclusion}

As a result of the research the following conclusions:

- in the EFES software package, an algorithm for solving multi-contact problems is implemented, which makes it possible to carry out numerical studies of the fracture of structures made of heavy reinforced cement with an explicit description of reinforcing elements, taking into account the fracture and fragmentation of materials;

- using the EFES software package, it is possible to conduct predictive studies of the protective properties of reinforced concrete structures upon impact, depending on the scheme and type of reinforcement in the design of promising structures.

This work was financially supported by the Government research assignment for ISPMS SB RAS, project no. FWRW-2021-0002.

\section{References}

[1] A.N.Birbraer, A.Yu.Roleder, Extreme Actions on Structures, St. Petersburg: St. Petersburg Polytechnic University Publishing House, 2009.

[2] L.F.Pereira, J.Weerheijm, L.J.Sluys, Simulation of Compaction and Crushing of Concrete in Ballistic Impact with a New Damage Model, Int. J. Impact Eng., 111(2018), 208-221.

[3] T.L.Teng, Y.A.Chu, F.A.Chang, H.S.Chin, Numerical Analysis of Oblique Impact on Reinforced Concrete, Cement Concrete Compos., 27(2005), 481-492.

[4] M.A.Iqbal, A.Rajput, P.Bhargava, Plain and Reinforced Concrete Targets Subjected to Projectile Impact, Proc. Eng., 173(2017), 138-144.

[5] Y.D.Zhang, Z.C.Lu, H.M.Wen, On the Penetration of Semi-Infinite Concrete Targets by Ogival-Nosed Projectiles at Different Velocities, Int. J. Impact Eng., 1292019, 128-140.

[6] R.Shao, C.Wu, Y.Su, Z.Liu, J.Liu, S.Xu, Numerical Analysis on Impact Response of UltraHigh Strength Concrete Protected with Composite Materials Against Steel Ogive-Nosed Projectile Penetration, Composite Struct., 220(2019), 861-874.

[7] A.Rajput, M.A.Iqbal, N.K.Gupta, Ballistic Performances of Concrete Targets Subjected to Long Projectile Impact, Thin-Walled Struct., 126(2018), 171-181.

[8] J.Liu, C.Wu, Y.Su, J.Li, R.Shao, G.Chen, Z.Liu, Experimental and Numerical Studies of Ultra-High Performance Concrete Targets Against High-Velocity Projectile Impacts, Eng. Struct., 173(2018), 166-179.

[9] F.Hu, H.Wu, Q.Fang, J.C.Liu, Impact Resistance of Concrete Targets Pre-Damaged by Explosively Formed Projectile (EFP) Against Rigid Projectile, Int. J. Impact Eng., 122(2018), 251-264. 
[10] Safety Aspects of Nuclear Power Plants in Human Induced External Events: Assessment of Structures, Safety Reports Series No. 87, Vienna: International Atomic Energy Agency, 2018.

[11] G.R.Johnson, T.J.Holmquist, An Improved Computational Constitutive Model for Brittle Materials, AIP Conf. Proc., 309(1984), 981-984.

[12] T.J.Holmquist, G.R.Johnson, W.H.Cook, A Computational Constitutive Model for Concrete Subjected to Large Strains, High Strain Rates, and High Pressures, Proc. of 14th Int. Symp. on Ballistics, 2(1993), 591-600.

[13] G.R.Johnson, High Velocity Impact Calculations in Three Dimension, J. Appl. Mech., 44(1977), no. 1, 95-100.

[14] P.A.Radchenko, S.P.Batuev, A.V.Radchenko, K.V.Vik, Adaptation Algorithm for the Finite Element Mesh in the Problems of the Fracture of Solids under Dynamic Loads, Computational Technologies, 25(2020), no. 1, 82-90 (in Russian). DOI: 10.25743/ICT.2020.25.1.006

[15] P.A.Radchenko, S.P.Batuev, A.V.Radchenko, Numerical analysis of concrete fracture under shock wave loading, Physical Mesomechanics, 24(2021), no. 1, 40-45.

DOI: $10.1134 / \mathrm{S} 1029959921010069$

[16] P.A.Radchenko, S.P.Batuev, A.V.Radchenko, Three-Dimensional Modeling of Deformation and Fracture of Heterogeneous Materials and Structures under Dynamic Loads (EFES 2.0), Federal Service for Intellectual Property. State Registration of Computer Programs, No. 2019664836 dated 11/14/2019.

\title{
Разрушение защитных конструкций из тяжелого армоцемента при взаимодействии с высокоскоростным ударником
}

\author{
Павел А. Радченко \\ Станислав П. Батуев \\ Андрей В. Радченко \\ Томск, Российская Федерация
}

Институт физики прочности и материаловедения СО РАН

\begin{abstract}
Аннотация. В работе численно моделируется разрушение железобетонной преграды из тяжелого армоцемента при нормальном взаимодействии с высокоскоростным титановым ударником. Начальная скорость ударника составляла $750 \mathrm{~m} / \mathrm{c}$. Задача ударного взаимодействия решается численно в трехмерной постановке в рамках феноменологического подхода механики сплошной среды. Численное моделирование проводится с использованием авторского программного комплекса EFES 2.0, позволяющего эффективно распараллелить вычислительный алгоритм. Разрушение бетона описывается моделью Джонсона - Холмквиста с учетом зависимости прочности бетона на сжатие и растяжение от скорости деформации. Вычислительный алгоритм учитывает разрушение материала и фрагментацию тел с образованием новых контактных и свободных поверхностей. Поведение материала ударника описывается упругопластической средой. В качестве критерия локального разрушения материала ударника принимается предельное значение интенсивности пластической деформации. Проведен подробный численный анализ динамики напряженно-деформируемого состояния железобетонной преграды и влияния ударно-волновых процессов на ее разрушение. Исследовано влияние армирования на сопротивление преграды из тяжелого армоцемента прониканию ударника
\end{abstract}

Ключевые слова: модель, разрушение, прочность, ударная волна, волна разгрузки, бетон, напряжение. 